\title{
Comparative study of biological activities of different extracts of root and whole plant materials of Ajuga bracteosa from Bhimber Azad Kashmir Pakistan
}

\author{
Muhammad Waqas $^{1 *}$, Tahseen Ghous ${ }^{1}$ and Beenish Akram ${ }^{1}$ \\ 1. Department of Chemistry, Mirpur University of Science and Technology, Mirpur, Azad Jammu \& Kashmir, \\ Pakistan \\ *Corresponding author's email: muhammadwaqas.79chemist@gmail.com \\ Citation \\ Muhammad Waqas, Tahseen Ghous and Beenish Akram. Comparative study of biological activities of different \\ extracts of root and whole plant materials of Ajuga bracteosa from Bhimber Azad Kashmir Pakistan. Pure and \\ Applied Biology. Vol. 10, Issue 4, pp1303-1311. http://dx.doi.org/10.19045/bspab.2021.100135
}

\begin{tabular}{llll}
\hline \hline Received: 15/12/2020 & Revised: 19/02/2021 & Accepted: 23/02/2021 & Online First: 13/03/2021 \\
\hline \hline
\end{tabular}

\section{Abstract}

Ajuga bracteosa is native to Himalayan region, Afghanistan, China and Malaysia. People of northern areas of Pakistan call it 'korri booti' as it has bitter taste. Ajuga bracteosa is ethnically used against malarial fever, diabetes, cancer, and sore throat. The theme of present work was to appraise the biological significance of Ajuga bracteosa through in vitro studies. n-Hexane, chloroform, and methanol extracts of root and whole plant materials were obtained via maceration. Qualitative and quantitative analysis of phytochemical constituents was done. The antioxidant potency was judged by DPPH (1,1-diphenyl-2-picrylhydrazyl) and ABTS (2,2azinobis-(3-ethylbenzothiazoline-6-sulphonic acid) free radical scavenging assays. Antimicrobial efficacy was assessed by agar disc diffusion method. Phytochemical review confirmed the existence of flavonoids, saponins, phenols, tannins, terpenoids, xanthoproteins, carbohydrates, and glycosides. Total flavonoid and total phenolic contents were shown as rutin and gallic acid equivalents respectively. Root extracts gave more significant results of DPPH and ABTS potential (100\% and $92 \%$ respectively) as compared to whole plant extracts (90\% and $75 \%$ respectively). A. bracteosa is a plentiful source of polyphenolic compounds. Polyphenolic compounds are thought as natural antioxidants because of their ability of hydrogen atom donation and presence as stable radical intermediates preventing further creation of free radicals in the body. Root extracts showed greater resistance against pathogens as compared to extracts of whole plant material.

Keywords: Antimicrobial activity; Antioxidant activity; Medicinal plants; Phytochemical screening

\section{Introduction}

Side effects of synthetic drugs have forced the medicinal world to return to nature i.e to use medicinal plants for healthcare. Humans have been cultivating plants since ancient times because of presence of natural compounds which have been used against various diseases [1, 2]. World health organization had stated that only 250 out of 20,000 types of medicinal plants were inspected for their potential against diseases. Only $25 \%$ of drugs is obtained using plants and above $80 \%$ of population of entire world is still dependent on indigenous medicinal plants to cure diseases $[3,4]$. Distinctive biodiversity of 
Pakistan includes more than 600 medicinal plants and people use these plants for medication purposes against fever, cough, and cold and to heal wounds. Ajuga bracteosa is native to Himalayan region, Afghanistan, China and Malaysia [5]. A. bracteosa being a promising herb has greater significance in rural areas of Pakistan and Azad Kashmir. People of northern areas of Pakistan call it 'korri booti' as it has bitter taste [6]. It belongs to family Labiatae of 266 genera and 301 species [7]. It had shown potential against worm infection, diabetes, cancer and fungal inflammation. Extracts of its leaves are used as blood purifier, against skin infections and malarial fever. Roots are used as an antidote to snake bite [8,9]. Different compounds of medical significance have also been isolated from $A$. bracteosa [10]. It is to our finest knowledge that no previous study has been done to compare its different parts for medicinal purposes. Thus present work was designed to compare presence of phytochemicals, antioxidant and antimicrobial potential of its different parts.

\section{Materials and Methods Plant collection}

Plants were collected from district Bhimber, Azad Jammu and Kahmir, Pakistan and identified by ethno-botanists of department of Botany, Mirpur University of Science and Technology, Mirpur, Pakistan. Plants were rinsed with water to remove soil contents and shade dried at room temperature.

\section{Preparation of extracts}

Roots were separated from remaining plants body in order to prepare two fractions i.e fraction of root material and fraction of whole plant material (stem and leaves) and crushed into a fine powder. Extraction was done by using three different solvents n-Hexane, chloroform, and methanol. $85 \mathrm{~g}$ powder of each fraction was extracted with $200 \mathrm{~mL}$ of one of mentioned solvents in increasing order of their polarity. Extracts were filtered and then evaporated at $40^{\circ} \mathrm{C}$ through rotary evaporator. Following formula was used to calculate percent recovery of extracts.

$\%$ Recovery $=$ (recovered mass of extract $/$ actual mass of sample powder) x 100

\section{Qualitative analysis of phytochemical} constituents

For phytochemical analysis extracts of both the fractions were tested to confirm the presence of bioactive constituents using standard phytochemical protocols.

\section{Total phenolic contents}

Deo et al. [11] with minor modifications was adopted for estimation of total phenolic contents. They were expressed as milli gram of gallic acid equivalent per gram of extract.

\section{Total flavonoid contents}

Determination of total flavonoid contents was quantified by adopting Ghous et al. [12] with minor modifications. They were expressed in terms of rutin equivalent.

\section{DPPH scavenging assay}

DPPH (1,1-diphenyl-2-picrylhydrazyl) scavenging activity was determined by adopting Ghous et al. [12] with minor modifications. All extracts $(0.5 \mathrm{~mL}$ and 1 $\mathrm{mL}$ ) were mixed with $3 \mathrm{~mL}$ and $2.5 \mathrm{~mL}$ of reaction mixture (DMSO and DPPH solutions) respectively. The absorbance was measured after incubation period of 0 , 15, and 30 minutes in darkness at $517 \mathrm{~nm}$. Percent scavenging activity $=\left[\left(\mathrm{A}_{\mathrm{c}}-\mathrm{A}_{\mathrm{i}}\right) / \mathrm{A}_{\mathrm{c}}\right]$ $\mathrm{x} 100$ formula was adopted for the calculation of percent scavenging activity; here $A_{c}$ is the absorbance value of standard and $A_{i}$ is the absorbance value of extract.

ABTS free radical cation decolourising assay

ABTS (2,2'-azinobis-(3ethylbenzothiazoline-6-sulphonic acid) free radical scavenging activity was estimated by adopting described method of Ghous et al. [12] with minor modifications. Reaction mixture was prepared by mixing potassium persulfate $(2.5 \mathrm{mM})$ and ABTS $(3 \mathrm{mM})$ and leaving for 16 hours in darkness for the generation of ABTS free radicals. All extracts $(20,100,200 \mu \mathrm{L})$ were allowed to mix with $\mathrm{ABTS}^{+}(1 \mathrm{~mL})$ and incubated for 20 minutes. Percent radical scavenging 
activity (\% RSA) was determined as: \% $\operatorname{RSA}=\left[\left(\mathrm{A}_{\mathrm{c}}-\mathrm{A}_{\mathrm{i}} / \mathrm{A}_{\mathrm{c}}\right)\right] \times 100$; here $\mathrm{A}_{\mathrm{c}}$ is absorbance value of standard and $A_{i}$ represents absorbance value of extracts.

\section{Antimicrobial activity}

For present research activity four bacterial pathogens (Escherichia coli, Bacillus pumilus, Bacillus subtilis, and Staphylicoccus aureus) were used. All these strains were reserved from Department of Biotechnology, Mirpur University of Science and Technology, Mirpur, Pakistan. Antimicrobial efficacy was assessed using agar disc diffusion method. Luria Bertani broth (L.B.Broth) medium and agar medium were mixed to prepare L.B Agar medium. It was transferred to sterilized plates of capacity of $20 \mathrm{~mL} /$ plate and left for solidification. Then fresh culture of pathogens was spread over it. Sterile discs of $6 \mathrm{~mm}$ diameter well soaked in extract solutions ( $5 \%$ ) were used. All these plates were incubated $37{ }^{\circ} \mathrm{C}$ for 24 hours. Antimicrobial efficacy was assessed by measuring zone of growth inhibition in mili-meter. Efficacy of extracts was expressed as zero for no efficacy, 1-5 mm for low efficacy, 6-10 mm for moderate efficacy and above $10 \mathrm{~mm}$ for high efficacy.

\section{Results and Dicussion \% Recovery of Extracts}

The recovery of extracts is as following; Root extracts (n-Hexane $=0.63 \%$, chloroform $=0.87 \%$, methanol $=3.71 \%$ ) Whole plant extracts (n-Hexane $0.67 \%$, chloroform $=1.64 \%$, methanol $=5.99 \%$ )

\section{Phytochemical screening}

Scientists have been working to know chemical composition of herbal medicines. Bioactive compounds have been isolated from medicinal plants to know about their pharmacological significance. Present comparative study has uncovered different phytochemicals in both the fractions. All extracts of both the fractions showed the presence of flavonoids, carbohydrates, tannins, saponins, diterpenes, steroids, and glycosides and absence of resins and carboxylic acids. Phenols were absent only in n-Hexane extracts. Quinones and amino acids were present in methanolic extracts and completely absent in n-Hexane extracts with the exception that they were present in chloroform extracts of whole plant material but absent in extract of root material. Xanthoproteins were found only in methanolic extracts. Alkaloids were present in all extracts of whole plant material and absent in all extracts of root material (Table $1)$.

\section{Total phenolic contents}

Polyphenols, important secondary metabolites of plants, can donate hydrogen atoms of phenolic hydroxyls to reduce reactive species of oxygen. Methanolic extract of root has $2.67 \mathrm{mg} / \mathrm{g}$ presence of total phenolic contents (TPC) as compared to $2.55 \mathrm{mg} / \mathrm{g}$ of same extract of whole plant material. Comparative presence of TPC in chloroform extracts of root material and whole plant material is $1 \mathrm{mg} / \mathrm{g}$ and 0.80 $\mathrm{mg} / \mathrm{g}$ respectively while $\mathrm{n}$ - Hexane extract of root material has $0.68 \mathrm{mg} / \mathrm{g}$ presence of TPC as compared to $0.52 \mathrm{mg} / \mathrm{g}$ in $\mathrm{n}-\mathrm{Hexane}$ extract of whole plant material. Thus comparative analysis showed that TPC had greater presence in extracts of root material as compared to extracts of whole plant material. All these results were measured as gallic acid equivalent (Table 2).

\section{Total flavonoid contents}

Comparative estimation of total flavonoid contents (TFC) in extracts of root and whole plant material was done against rutin hydrate calibration curve. Methanolic extract of root has $7.7 \mathrm{mg} / \mathrm{g}$ TFC as compared to $7.4 \mathrm{mg} / \mathrm{g}$ in same extract of whole plant material. Comparative presence of TFC in chloroform extracts of root and whole plant materials is $5.7 \mathrm{mg} / \mathrm{g}$ and $4.97 \mathrm{mg} / \mathrm{g}$ respectively while $\mathrm{n}-\mathrm{Hexane}$ extract of root material has $4.45 \mathrm{mg} / \mathrm{g}$ presence of TFC as compared to $3.9 \mathrm{mg} / \mathrm{g}$ TFC in extract of whole plant material. Thus comparative analysis exposed greater presence of TFC in root extracts as compared to whole plant extracts (Table 3). 
Table 1. Analysis of phytochemical constituents of extracts of root and whole plant fractions of $A$. bracteosa

\begin{tabular}{|c|c|c|c|c|c|c|c|}
\hline $\begin{array}{c}\text { Serial } \\
\text { numbe } \\
\mathbf{r}\end{array}$ & $\begin{array}{c}\text { Phytochemical } \\
\text { constituents }\end{array}$ & \multicolumn{2}{|c|}{ R-Hexane } & \multicolumn{2}{c|}{ Chloroform } & \multicolumn{2}{c|}{ Methanol } \\
\cline { 4 - 8 } & Root & $\begin{array}{c}\text { Whole } \\
\text { plant }\end{array}$ & Root & $\begin{array}{c}\text { Whole } \\
\text { plant }\end{array}$ & Root & Whole plant \\
\hline 1 & Flavonoids & $\checkmark$ & $\checkmark$ & $\checkmark$ & $\checkmark$ & $\checkmark$ & $\checkmark$ \\
\hline 2 & Carbohydrates & $\checkmark$ & $\checkmark$ & $\checkmark$ & $\checkmark$ & $\checkmark$ & $\checkmark$ \\
\hline 3 & Phenols & $\times$ & $\times$ & $\checkmark$ & $\checkmark$ & $\checkmark$ & $\checkmark$ \\
\hline 4 & Tannins & $\checkmark$ & $\checkmark$ & $\checkmark$ & $\checkmark$ & $\checkmark$ & $\checkmark$ \\
\hline 5 & Resins & $\times$ & $\times$ & $\times$ & $\times$ & $\times$ & $\times$ \\
\hline 6 & Carboxylic acids & $\times$ & $\times$ & $\times$ & $\times$ & $\times$ & $\times$ \\
\hline 7 & Saponins & $\checkmark$ & $\checkmark$ & $\checkmark$ & $\checkmark$ & $\checkmark$ & $\checkmark$ \\
\hline 8 & Quinones & $\times$ & $\times$ & $\times$ & $\checkmark$ & $\checkmark$ & $\checkmark$ \\
\hline 9 & Xanthoproteins & $\times$ & $\times$ & $\times$ & $\times$ & $\checkmark$ & $\checkmark$ \\
\hline 10 & Amino acids & $\times$ & $\times$ & $\times$ & $\checkmark$ & $\checkmark$ & $\checkmark$ \\
\hline 11 & Diterpenes & $\checkmark$ & $\checkmark$ & $\checkmark$ & $\checkmark$ & $\checkmark$ & $\checkmark$ \\
\hline 12 & Steroids & $\checkmark$ & $\checkmark$ & $\checkmark$ & $\checkmark$ & $\checkmark$ & $\checkmark$ \\
\hline 13 & Glycosides & $\checkmark$ & $\checkmark$ & $\checkmark$ & $\checkmark$ & $\checkmark$ & $\checkmark$ \\
\hline 14 & Alkaloids & $\times$ & $\checkmark$ & $\times$ & $\checkmark$ & $\times$ & $\checkmark$ \\
\hline
\end{tabular}

Table 2. Total Phenolic Contents in extracts of root and whole Plant fractions of $A$. bracteosa

\begin{tabular}{|c|c|c|c|}
\hline \multirow{2}{*}{ Plant material } & \multicolumn{3}{|c|}{ TPC (mg/g) in different extracts } \\
\cline { 2 - 4 } & n-Hexane & Chloroform & Methanol \\
\hline Root & 0.68 & 1 & 2.67 \\
\hline Whole plant & 0.52 & 0.80 & 2.55 \\
\hline
\end{tabular}

$\mathrm{TPC}=$ Total Phenolic Contents

Table 3. Total Flavonoid Contents in extracts of root and whole Plant fractions of $A$. bracteosa

\begin{tabular}{|c|c|c|c|}
\hline \multirow{2}{*}{ Plant material } & \multicolumn{3}{|c|}{ TFC (mg/g) in different extracts } \\
\cline { 2 - 4 } & n-Hexane & Chloroform & Methanol \\
\hline Root & 4.45 & 5.7 & 7.7 \\
\hline Whole plant & 3.9 & 4.97 & 7.4 \\
\hline
\end{tabular}

TFC= Total Flavonoid Contents

\section{DPPH scavenging assay}

Simplicity, quick analysis and direct measurement of inhibition are the characteristics which make DPPH a frequently used antioxidant assay [13] . Extracts having ability of donation of hydrogen atom to stable free radical of DPPH are thought good antioxidants. All extracts of Ajuga bracteosa have displayed significant scavenging potential in case of DPPH assay. The present research work revealed that extracts of root material have greater scavenging potential than extracts of whole plant material and also exposed that scavenging potential exhibited decreasing trend from organic polar to organic non-polar extracts. Initially scavenging potential was compared by using $0.5 \mathrm{~mL}$ of all extracts of root and whole plant material. Methanolic extract of root material exhibited $89 \%$ scavenging potential as compared to $75 \%$ scavenging potential of methanolic extract of whole plant material. Chloroform extracts of root and whole plant material have comparative scavenging potential $71 \%$ and $57 \%$ respectively. $26 \%$ scavenging potential was exhibited by n-Hexane extract of root 
material as compared to $15 \%$ potential of same extract of whole plant material. It is a general observation that scavenging potential will increase by increasing volume of extacts. Thus volume of all extracts was increased to $1 \mathrm{~mL}$. This change displayed incredible increase in results.
Increased Scavenging potential for methanolic, chloroform, and n-Hexane extracts of root material is $100 \%, 83 \%$, and $39 \%$ respectively and $90 \%, 72 \%$, and 32 $\%$ respectively in case of whole plant material (Table 4).

Table 4. DPPH Percent Inhibition Potency of extracts of root and whole plant fractions of A. bracteosa

\begin{tabular}{|c|c|c|c|c|c|c|}
\hline \multirow{2}{*}{$\begin{array}{c}\text { Plant } \\
\text { material }\end{array}$} & \multicolumn{5}{|c|}{ \% Scavenging Potential at different concentrations } \\
\cline { 2 - 7 } & \multicolumn{5}{|c|}{$(\mathbf{0 . 5}$ mL) } & \multicolumn{3}{c|}{$\mathbf{( 1 ~ m L )}$} \\
\cline { 2 - 7 } & n-Hexane & Chloroform & Methanol & n-Hexane & Chloroform & Methanol \\
\hline Root & 26 & 71 & 89 & 39 & 83 & 100 \\
\hline Whole plant & 15 & 57 & 75 & 32 & 72 & 90 \\
\hline
\end{tabular}

ABTS radical cation decolourising assay Outfitting of free radicals can be assessed by ABTS assay. This method has advantage over DPPH, sensitive to only acidic $\mathrm{pH}$, in terms of its application at different $\mathrm{pH}$ values [14]. In this work $20 \mu \mathrm{L}, 100 \mu \mathrm{L}$, and $200 \mu \mathrm{L}$ of extracts of root material were compared with the same volume of extracts of whole plant material to compare their antioxidant potential. Comparative results of $20 \mu \mathrm{L}$ volume of all extracts revealed that inhibition potential of root extracts (nHexane $=0.26 \%$, chloroform $=1.8 \%$, methanol $=48 \%$ ) was greater than that of extracts of whole plant material (nHexane $=0.2 \%$, chloroform $=1.6 \%$, methanol $=13.2 \%$ ). Significant increase in inhibition potential of all extracts was observed by increasing their volume up to $100 \mu \mathrm{L}$. n-Hexane extract of root material showed $1.8 \%$ inhibition potential as compared to $1.06 \%$ inhibition potential of whole plant $n-H e x a n e$ extract. Chloroform and methanol extract of root material depicted $3.9 \%$ and $74 \%$ inhibition potential respectively as compared to $3.9 \%$ and $34 \%$ inhibition potential of whole plant material in a respective manner. Finally outstanding results were achieved by increasing volume up to $200 \mu \mathrm{L}$ of all extracts. Inhibition potential of n-Hexane, chloroform, and methanol extracts of root material was in order $4.2 \%, 7.1 \%$ and 92 $\%$ respectively while the inhibition potential of n-Hexane, chloroform and methanol extracts of whole plant material was in order $2.38 \%, 5.3 \%$, and $75 \%$ respectively. From this research it is made known that antioxidant potential of root extracts is greater than that of extracts of whole plant material (Table $5 \& 6$ ).

Table 5. Percent inhibition of free radicals by extracts (Root) of A. bracteosa by ABTS decolourising assay

\begin{tabular}{|c|c|c|c|}
\hline \multirow{2}{*}{ Extracts } & \multicolumn{3}{|c|}{ \% Inhibition at different concentrations } \\
\cline { 2 - 4 } & $\mathbf{2 0} \boldsymbol{\mu} \mathbf{L}$ & $\mathbf{1 0 0} \boldsymbol{\mu} \mathbf{L}$ & $\mathbf{2 0 0} \boldsymbol{\mu L}$ \\
\hline n-Hexane & 0.26 & 1.8 & 4.2 \\
\hline Chloroform & 1.8 & 3.9 & 7.1 \\
\hline Methanol & 48 & 74 & 92 \\
\hline
\end{tabular}


Table 6. Percent inhibition of free radicals by extracts (whole plant) of $A$. bracteosa by ABTS decolourising assay

\begin{tabular}{|c|c|c|c|}
\hline \multirow{2}{*}{ Extracts } & \multicolumn{3}{|c|}{ \% Inhibition at different concentrations } \\
\cline { 2 - 4 } & $\mathbf{2 0} \boldsymbol{\mu} \mathbf{L}$ & $\mathbf{1 0 0} \boldsymbol{\mu L}$ & $\mathbf{2 0 0} \boldsymbol{\mu L}$ \\
\hline n-Hexane & 0.2 & 1.06 & 2.38 \\
\hline Chloroform & 1.6 & 3.9 & 5.3 \\
\hline Methanol & 13.2 & 34 & 75 \\
\hline
\end{tabular}

\section{Antimicrobial activity}

Whole world including Pakistan is facing the growing resistance of microbes against numerous synthetic drugs because of their improper and repeated usage. Increasing resistance of bacteria against synthetic drugs has forced the researchers to return to herbal medicines [15]. A. bracteosa being a rich source of natural therapeutic agents is reported to show well acknowledged efficacy against microbial diseases like Diarrhea, Cholera and Typhoid fever. In this work antimicrobial activity of extracts of both the fractions of $A$. bracteosa was compared. Low sensitivity was shown by methanol extract of root against $S$. aureus, and B. pumilus (2 $\mathrm{mm}$ against each) and medium range sensitivity against $B$. subtilis and $E$. coli i.e $6 \mathrm{~mm}$ and $8 \mathrm{~mm}$ respectively. Methanol extract of whole plant material depicted medium sensitivity against $B$. subtilis, S. aureus, $(8 \mathrm{~mm}$, and $10 \mathrm{~mm}$ respectively) and higher sensitivity against
B. pumilus and E. coli (11mm against each). Chloroform extract of root material expressed his medium sensitivity against all pathogens $(E$. coli $=9 \mathrm{~mm}$, B. subtilis $=9$ $\mathrm{mm}$, and $B$. pumilus $=7 \mathrm{~mm}$ ) while the same extract of whole plant material showed again medium sensivity against all used pathogen $(E$. coli $=10 \mathrm{~mm}$, B. subtilis $=7$ $\mathrm{mm}$, and $B$. pumilus $=8 \mathrm{~mm}$ ). Sensitivity of chloroform extract of root and whole plant material was lower (4 mm) and higher (12) respectively against S.aureus. n-Hexane extract of both the fractions showed medium range sensitivity against $B$. subtilis, B. pumilus, and $S$. aureus i.e $7 \mathrm{~mm}$, $10 \mathrm{~mm}$, and $6 \mathrm{~mm}$ respectively in case of root material and $5 \mathrm{~mm}, 6 \mathrm{~mm}$, and $10 \mathrm{~mm}$ respectively in case of whole plant material. n-Hexane extract of root displayed higher sensitivity against $E$. coli $(11 \mathrm{~mm})$ and same extract of whole plant material showed medium sensitivity against same pathogen $(7 \mathrm{~mm})$ (Table 7$)$.

Table 7. Antimicrobial activity of root and whole plant extracts of $A$. bracteosa

\begin{tabular}{|c|c|c|c|c|c|c|}
\hline \multirow{2}{*}{ Strains } & \multicolumn{6}{|c|}{ Zone of inhibition (mm) by different extracts } \\
\cline { 2 - 7 } & $\begin{array}{c}\text { n-Hexane } \\
\text { (whole } \\
\text { plant) }\end{array}$ & $\begin{array}{c}\text { Chloroform } \\
\text { (whole } \\
\text { plant) }\end{array}$ & $\begin{array}{c}\text { Methanol } \\
\text { (whole } \\
\text { plant) }\end{array}$ & $\begin{array}{c}\text { n-Hexane } \\
\text { (root) }\end{array}$ & $\begin{array}{c}\text { Chloroform } \\
\text { (root) }\end{array}$ & $\begin{array}{c}\text { Methanol } \\
\text { (root) }\end{array}$ \\
\hline $\begin{array}{c}\text { Escherichia } \\
\text { coli }\end{array}$ & 7 & 10 & 11 & 11 & 9 & 8 \\
\hline $\begin{array}{c}\text { Bacillus } \\
\text { subtilis }\end{array}$ & 5 & 7 & 8 & 7 & 9 & 6 \\
\hline $\begin{array}{c}\text { Bacillus } \\
\text { pumilus }\end{array}$ & 6 & 8 & 11 & 10 & 7 & 2 \\
\hline $\begin{array}{c}\text { Staphylococcus } \\
\text { aureus }\end{array}$ & 10 & 12 & 10 & 6 & 4 & 2 \\
\hline
\end{tabular}

Herbal plants have pivot place in folk medicines of various societies [16]. These plants have marvellous presence of flavonoids and phenolic contents which are important biologically active compounds
[17]. These phytochemicals at present are getting increased attention as these are essential for reproduction and better growth of plants. Phenolic and flavonoid contents are important constituents of polyphenolic 
compounds [18]. They possess diverse biological activities like antioxidant, astringent, anti-inflammation, anticancer and antibacterial activity [19]. Our present study has unveiled the enriched presence of these phytochemicals in A. bracteosa. The comparative presence of these phytochemicals is determined by the polarity of solvents used for extraction. Their huge amount is found in more polar extracts which decreased with decrease in polarity of extracts. Chloroform and nHexane extracts have lesser amount of these compounds as compared to methanolic extracts. Methanolic extract of root material has more presence of these secondary metabolites as compared to the same extract of whole plant material.

Metabolic and other activities in the body generate reactive oxygen and nitrogen species which are free radicals in nature. These free radicals create a chain reaction in the body producing oxidative stress which in turn causes neurodegenerative diseases, cancer, heart diseases and aging process[20-22]. Antioxidants are needed to outfit these reactive species. At present synthetically prepared antioxidants are available but with a disadvantage of side effects. Thus plants are considered as prospective source of natural antioxidants [16]. In our work antioxidant potential of root and whole plant materials of $A$. bracteosa was appraised and compared by DPPH and ABTS free radical scavenging assays. A. bracteosa is plentiful source of polyphenolic compounds. Polyphenolic compounds are thought as natural antioxidants because of their ability of hydrogen atom donation and presence as stable radical intermediates preventing further creation of free radicals in the body [23]. Our study showed more presence of these compounds in methanolic extracts of root and whole plant materials as compared to chloroform and n-Hexane extracts of the same plant materials. These compounds are significantly higher in amount in root material extracts as compared to extracts of whole plant material. Thus greater antioxidant activity was shown by extracts of root material in both the free radical scavenging assays. Decline in scavenging activity of extracts of both the root and whole plant materials was observed with decrease in polarity of the solvents used for extracts. However, all extracts of root material showed more improved and significant scavenging activity as compared to the extracts of whole plant material. Plants have been a subject of interest against various pathogenic infections [24]. While appraising the efficacy of extracts of root and whole plant materials of $A$. bracteosa against pathogens it was revealed that all extracts showed significant resistance against $E$. coli and average resistance was observed against $B$. subtilis. Quite interestingly methanolic extract of root material showed very low resistance against $B$. pumilus and $S$. aureus as compared to the significant resistance of methanolic extract of whole plant material against the same pathogens. Thus our study has not only revealed all possible therapeutic effects of $A$. bracteosa but also unveiled the supremacy of root material over whole plant material of $A$. bracteosa through their comparative analysis.

\section{Conclusion}

All comparative results of this research work revealed the greater importance of root over other parts of A. bracteosa in pharmacology. Keeping in view all these results it can be inferred that $A$. bracteosa is a prospective source of secondary metabolites playing vital role as antioxidant and antibacterial agents. It also proved that roots have greater presence of these substances as compared to other parts of the plant. This research also provides all those directions which can extend medical worth of the plant through isolation along with characterization of natural compounds.

\section{Authors' contributions}

Conceived and designed the experiments: $M$ Waqas \& $\mathrm{T}$ Ghous, Performed the experiments: $M$ Waqas \& B Akram, Analyzed the data: M Waqas \& T Ghous, Contributed materials/ analysis/ tools: U 
Laboratory, Wrote the paper: M Waqas \& B Akram.

\section{References}

1. Russo D, Miglionico R, Carmisino M, Bisaccia F, Andrade PB, Valentao P, Milella L \& Armentano MF (2018). A comparative study on phytochemical profiles and biological activities of Sclerocarybirrea (A. Rich.) Hochst leaf and bark extracts. Int J Mol Sci 19(1): 186.

2. Mahmood A, Mahmood A \& Tabassum A (2011). Ethnomedicinal survey of plants from District Sialkot, Pakistan. J Appl Pharm 3: 212-220.

3. Mahmood A, Mahmood A, Shaheen H, Qureshi RA, Sangi Y \& Gilani SA (2011). Ethno medicinal survey of plants from district Bhimber Azad Jammu and Kashmir, Pakistan. J Med Plant Res 5(11): 2348-2360.

4. Malik RN, Husain SZ \& Nazir I (2010). Heavy metal contamination and accumulation in soil and wild plant species from industrial area of Islamabad, Pakistan. Pak J Bot 42(1): 291-301.

5. Shad AA, Zeeshan M, Fazal H, Shah HU, Ahmed S, Abeer H, Abd_Allah EF, Ullah R, Afridi H, Tariq A, Adnan M \& Asma (2016). Physio-chemical evaluation and biological activity of Ajuga bracteosa wall and Viola odoroto Linn. Afr J Tradit Complement Altern Med 13(2): 40-46.

6. Kokab H, Saiqa A, Ghous T, Rozina GM, Anum N, Irsa S \& Kalsoom A (2017). Phytochemical screening, alpha-glucosidase inhibition, antibacterial and antioxidant potential of Ajuga bracteosa extracts. Curr Pharm Biotechnol 18(4): 336-342.

7. Upadhyay SU, Patel VB, Patel AA, Upadhyay UM \& Patel NM (2012). AJUGA BRACTEOSA: A PROMISING HERB. Pharma Sci Monitor 3(4).

8. Kayani WK, Dilshad E, Ahmed T, Ismail H \& Mirza B (2016). Evaluation of Ajuga bracteosa for antioxidant, anti-inflammatory, analgesic, antidepressant and anticoagulant activities. BMC Complement Altern Med 16(1): 375.

9. Kayani WK, Fattahi M, Palazon J, Cusido RM \& Mirza B (2016). Comprehensive screening of influential factors in the Agrobacterium tumefaciens-mediated transformation of the Himalayan elixir: Ajuga bracteosa Wall. ex. Benth. $J$ Appl Res Med Arom Plants 3(4): 151159.

10. Pal, A \& Pawar R (2011). A Study on Ajuga bracteosa wall ex. Benth for analgesic activity. Int J Cur Biol Med Sci 1(2): 12-14.

11. Deo P, Hewawasam E, Karakoulakis A, Claudie DJ, Nelson R, Simpson BS, Smith NM \& Semple SJ (2016). In vitro inhibitory activities of selected Australian medicinal plant extracts against protein glycation, angiotensin converting enzyme (ACE) and digestive enzymes linked to type II diabetes. BMC Complement Altern Med 16(1): 435.

12. Ghous T, Aziz N, Mehmood Z \& Andleeb S (2015). Comparative study of antioxidant, metal chelating and antiglycation activities of Momordica charantia flesh and pulp fractions. Pak J Pharm Sci 28(4).

13. Kaewnarin K, Hataichanoka, Shank L \& Rakariyatham N (2014). Antioxidant and antiglycation activities of some edible and medicinal plants. Chiang Mai J Sci 41(1): 105-116.

14. Shalaby EA \& Shanab SM (2013). Antioxidant compounds, assays of determination and mode of action. $A f r$ J Pharm Pharmacol 7(10): 528-539.

15. Mehmood B, Dar KK, Ali S, Awan UA, Nayyer AQ, Ghous T \& Andleeb $S$ (2015). In vitro assessment of antioxidant, antibacterial and phytochemical analysis of peel of Citrus sinensis. Pak J Pharm Sci 28(1). 
16. Ghasemzadeh A, Jaafar HZ \& Rahmat A (2010). Antioxidant activities, total phenolics and flavonoids content in two varieties of Malaysia young ginger (Zingiber officinale Roscoe). Molecules 15(6): 4324-4333.

17. Aliyu AB, Ibrahim MA, Musa AM, Musa AO, Kiplimo JJ \& Oyewale AO (2013). Free radical scavenging and total antioxidant capacity of root extracts of Anchomanes difformis Engl.(Araceae). Acta Pol Pharm 70(1): 115-21.

18. Sultana M, Verma PK, Raina R, Prawez S \& Dar MA. (2012). Quantitative analysis of total phenolic, flavonoids and tannin contents in acetone and n-hexane extracts of Ageratum conyzoides. Int J ChemTech Res 4: 996-9.

19. Jeong MR, Kim HY \& Cha JD (2009). Antimicrobial activity of methanol extract from Ficus carica leaves against oral bacteria. J Bacteriol Virol 39(2): 97-102.
20. Aljohi A, Nasri SM \& Ahmed N (2016). Antiglycation and antioxidant properties of Momordica charantia. PloS One 11(8): 0159985.

21. Lekshmi R \& Mini S (2013). Evaluation of antioxidant and antiglycation activities of various solvent fractions of Cissus quadrangularis stem. Int $J$ Pharm Biosci 4: 1259-1268.

22. López-Alarcón C \& Denicola A (2013). Evaluating the antioxidant capacity of natural products: A review on chemical and cellular-based assays. Anal Chim Acta 763: 1-10.

23. Githinji P (2017). Quantitative Analysis of Total Phenolic Content in Avocado (Persia Americana) Seeds in Eastern Province of Kenya.

24. Jakovljević DZ et al. (2015). Secondary metabolite content and in vitro biological effects of Ajuga chamaepitys (L.) Schreb. subsp. chamaepitys. Arch Biol Sci 67(4): 1195-1202. 